\title{
Production of hydrogen gas from biomass oil palm empty fruit bunch using electrolysis method
}

\author{
Resti Yunia Amri ${ }^{1,3}$, Annisa Khafiya Saba ${ }^{1,3}$, Asrina Asfarina ${ }^{1}$ and Rudy Syah Putra ${ }^{1,2 *}$ \\ ${ }^{1}$ Department of Chemistry, Faculty of Mathematics and Natural Sciences, Universitas Islam Indonesia, Jl. Kaliurang Km \\ 14.5, Yogyakarta 55584, Indonesia \\ ${ }^{2}$ New and Renewable Energy Research Group, Faculty of Mathematics and Natural Sciences, Universitas Islam \\ Indonesia, Jl. Kaliurang Km 14.5, Yogyakarta 55584, Indonesia \\ ${ }^{3}$ Laboratorium Mahasiswa, Universitas Islam Indonesia, Jl. Kaliurang Km 14.5, Yogyakarta 55584, Indonesia
}

\begin{abstract}
Biomass oil palm empty fruit bunch (OPEFB) is a sustainable source for hydrogen production. OPEFB and $\mathrm{FeCl}_{3} .6 \mathrm{H}_{2} \mathrm{O}$ oxidizers $(0.1,0.2,0.3$ and $0.4 \mathrm{~mol})$ were refluxed at $90-98{ }^{\circ} \mathrm{C}$ for 5 hours. The acquired aliquot was used to produce $\mathrm{H}_{2}$ with variation of storage time (fresh aliquot and old aliquot). The production of $\mathrm{H}_{2}$ was carried out by electrolysis method where the aliquot was diluted by ratio of 1:10. The electrolysis was carried out using two electrodes as anode (titanium) and cathode (stainless steel) with DC current voltage $15 \mathrm{~V}$. The principle of gas mass transfer in the vessel following Bernoulli's principle was used to calculate the volume of $\mathrm{H}_{2}$ formed. The change of current by formation of $\mathrm{H}_{2}$ were used to calculate the volume of $\mathrm{H}_{2}$ following Faraday's law. The results showed that the storage time of the solution affects the production time of $\mathrm{H}_{2}$. The oxidizer concentration has no effect on the $\mathrm{H}_{2}$ production in the fresh solution but has effect on the old solution. The best solution to produce $\mathrm{H}_{2}$ is a 0.1 mol oxidizer solution with a production time of 8 minutes. The produced $\mathrm{H}_{2}$ can be used in power generation by a fuel cell process.
\end{abstract}

\section{Introduction}

Environmental pollution and energy crisis are one of many problems faced in this era. Waste and air pollution around us can causes the environment dirty and pose a threat to life like an epidemic that can threaten human life. Therefore, handling is needed to overcome these problems, one of which is utilizing waste as an alternative energy source. Palm empty fruit bunch (OPEFB) is an alternative energy source that can overcome problems in the environment by providing advantages such as the availability of many in the area of oil palm farming and it can be used in the production of hydrogen gas [1].

Hydrogen is the most common element found in nature, but hydrogen in nature is not in gaseous form and combines with other elements such as combined $\mathrm{H}_{2} \mathrm{O}$ water and hydrograph. Hydrogen is also found in many organic compounds. To get a pure hydrogen can be done with electrolysis method. Hydrogen has high energy and the engine that burns pure hydrogen hardly produces pollution. Electrolysis method can be used to overcome environmental pollution and energy crisis by utilizing electrochemical reaction to convert organic waste into biomass fuel. In this method we can use both homogeneous and heterogeneous catalysts in which heterogeneous catalysts have the advantage of being environmentally friendly, inexpensive, and reusable [2].
This research uses electrolysis method with gas mass transfer principle to calculate the volume of hydrogen that is formed. The electrolyte used was prepared based on research conducted by Gong et al. [3] The change in hydrogen formation is used to calculate the hydrogen volume calculation follows Faraday's law. This research was previously conducted by Wahyono et al. [4] electrolysis of seawater by the addition of acetic acid catalyst to analyze the production of hydrogen gas. In this study, modification of electrolysis was done by using solution of OPEFB refluxed at $80-90{ }^{\circ} \mathrm{C}$ with mixture of different oxidizer concentration and acid catalysts for the production of $\mathrm{H}_{2}$ and this study examines the effect of storage of the solution to the production of $\mathrm{H}_{2}$ produced.

\section{Materials and methods}

\subsection{Materials and equipment}

This experiment used Oil Palm Empty Fruit Bunch (OPEFB) obtained from PT. Perkebunan Kelapa Sawit Sungai Parit, Penajaman North Paser, East Kalimantan, Indoneisa and $\mathrm{FeCl}_{3} \cdot 6 \mathrm{H}_{2} \mathrm{O}$ (CAS-No : 10025-77-1, Merck, Germany). Reflux process used a reflux set device with a $250 \mathrm{~mL}$ round bottom flask. The electrode used are stainless steel with dimensions of $7 \mathrm{~cm}$ (long) x $1.5 \mathrm{~cm}$ (wide) and titanium rode with dimension of $7 \mathrm{~cm}$ (long)

\footnotetext{
* Corresponding author: rudy.syahputra@uii.ac.id
} 
$1.0 \mathrm{~cm}$ (wide) x $3 \mathrm{~mm}$ (thick). All the solution preparation use deionized water.

\subsection{Reflux process}

Before use, the OPEFB biomass sample must be dried under the sunlight and then cut into small pieces with a length of approximately $\pm 1 \mathrm{~cm}$. Put in the oven for 24 hours at $62{ }^{\circ} \mathrm{C}$ to reduce the water rate. 4 grams of OPEFB and $\mathrm{FeCl}_{3} \cdot 6 \mathrm{H}_{2} \mathrm{O}(0,1 ; 0,2 ; 0,4 \mathrm{~mol})$, were mixed, $\mathrm{HCl}$ solution $(10 \mathrm{~mL})$ and deionized water $(90 \mathrm{~mL})$ was added. The suspension was heated to reflux at $90-98{ }^{\circ} \mathrm{C}$ for 5 hours under stirring. After a certain reaction time, the solution was cooled to room temperature and filtered. Then filtrate was used as an electrolyte in hydrogen gas production.

\section{$2.3 \mathrm{H}_{2}$ production}

The $\mathrm{H}_{2}$ volume of the solution experimentally was measured using 2 electrodes (stainless steel and $\mathrm{Ti}$ ) in reactor as shown in Fig. 1. The filtrate was diluted by the ratio 1:10 into $100 \mathrm{~mL}$ to keep the $\mathrm{pH}$ solution from being too acid and it used as an electrolyte in the electrolysis cell to produce hydrogen.

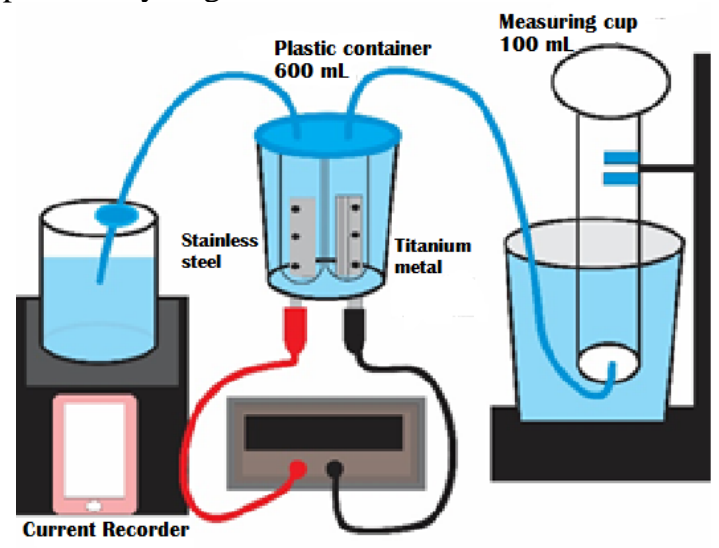

Fig. 1. Illustration of hydrogen gas production tools using electrolysis method

In this experiment, the $\mathrm{H}_{2}$ volume of the solution was calculated by the principle of water mass displacement is equivalent to the gas volume following the principle of Bernoulli that is "the higher the fluid speed the lower the pressure it becomes and the lower the fluid speed the higher the pressure it becomes", as shown in the following Eq. 1:

$$
P_{1}+\frac{1}{2} P V_{1}^{2}+\rho g h_{1}=P_{2}+\frac{1}{2} P V_{2}^{2}+\rho g h_{2}
$$

The current during the hydrogen production process was measured using a multimeter (KW06-796, Krisbow, China). The resulted current from multimeter then used as data to confirm the hydrogen production experimentally. The gas hydrogen volume experimentally calculated based on the time required to produce a hydrogen bubble using the ideal gas equation shown in Eq. 2 and Eq. 3:

$$
\begin{gathered}
P V=n R T \\
V=\frac{n R T}{P} \\
n=\frac{M}{M r}
\end{gathered}
$$

The mass value of the hydrogen gas can be calculated using Faraday's Law as shown in equation 4 where the electrical charge is calculated by the integral from the current measurement exponential equation.

$$
\begin{gathered}
M=\frac{Q \times A r}{n \times F} \\
I(A)=y \times e^{(x) \times t} \\
\int_{0}^{300} I d t=\left(\frac{y}{x}\right)(\exp (x \times 300)-\exp (x \times 0))
\end{gathered}
$$

\section{Results and discussion}

In this research, the degraded biomass solution was made by using $\mathrm{FeCl}_{3} \cdot 6 \mathrm{H}_{2} \mathrm{O}$ oxidizer with different concentrations and storage times. Variations $\mathrm{FeCl}_{3} \cdot 6 \mathrm{H}_{2} \mathrm{O}$ concentration and storage time were used to determine the optimal concentration in the production of hydrogen gas.

\section{1 $\mathrm{H}_{2}$ production by fresh solution}

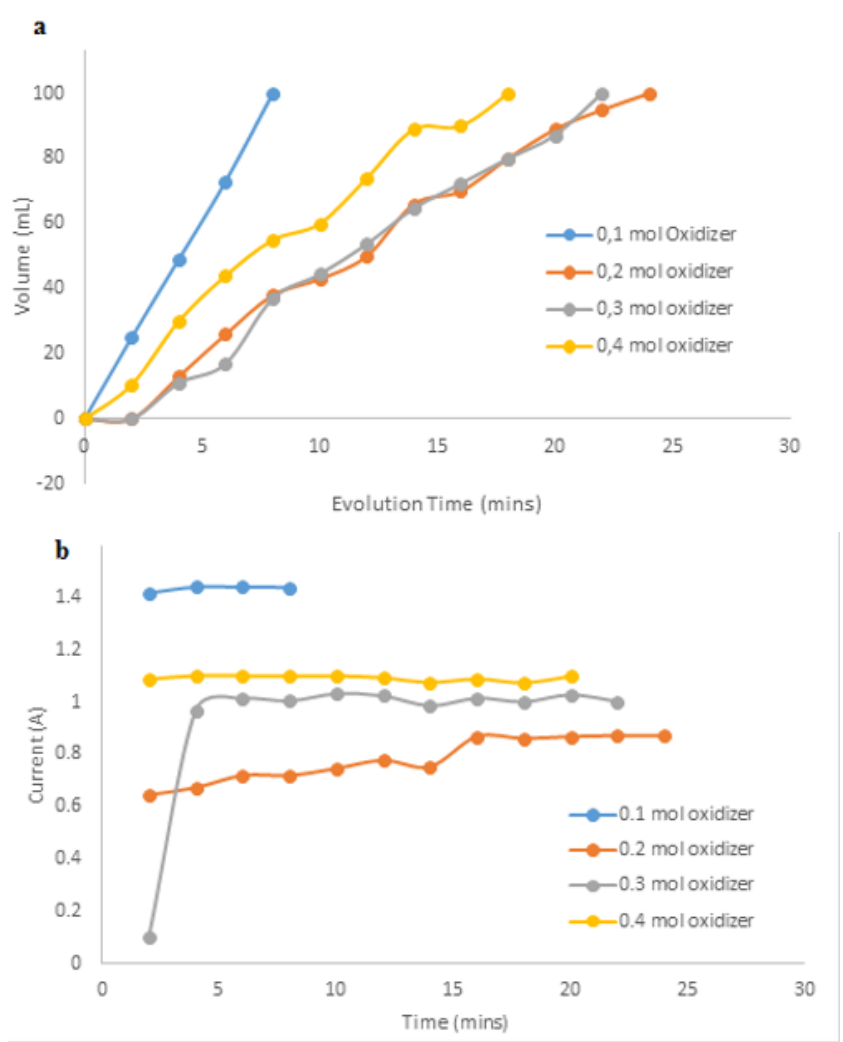

Fig. 2. (a) volume of hydrogen gas experimentally by fresh solution, (b) current applied during hydrogen gas production 
Fig. 2(a) shows that a fresh solution with a $0.1 \mathrm{~mol}$ oxidizing concentration is the solution that produces the most stable and fastest hydrogen gas. This solution produces $100 \mathrm{~mL}$ of hydrogen gas within 8 minutes. The time required to produce $100 \mathrm{~mL}$ of hydrogen gas in solution with $0.2,0.3$ and 0.4 mol oxidizing concentrations respectively is 24,22 and $18 \mathrm{~min}$. Fig. 2(b) shows the current used during the process of producing hydrogen gas. The DC current supplied to the reactor is a stable current. This current data is then used to calculate the volume of hydrogen gas produced under Faraday's law shown in Table 1.

\section{$3.2 \mathrm{H}_{2}$ production by old solution}
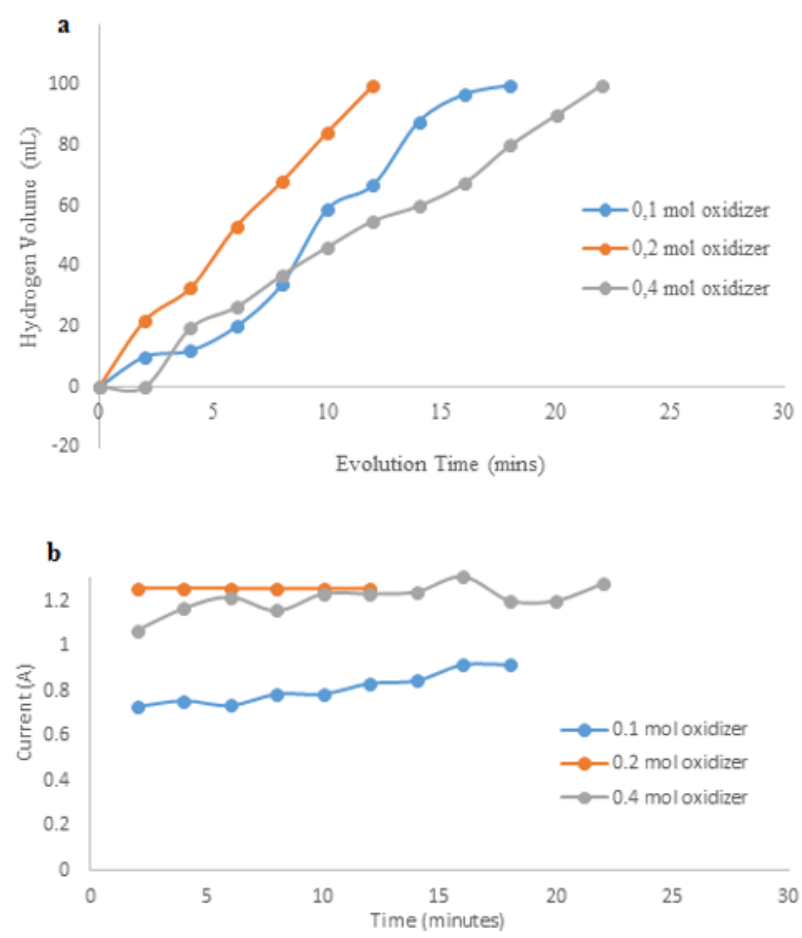

Fig. 3. (a) volume of hydrogen gas experimentally by old solution, and (b) current applied during hydrogen gas production

Fig. 3(a) shows that the old solution with a $0.2 \mathrm{~mol}$ oxidizing concentration is the solution that produces the most stable and fastest hydrogen gas. This solution produces $100 \mathrm{~mL}$ of hydrogen gas within 12 minutes. The time required to produce $100 \mathrm{~mL}$ of hydrogen gas in 0.1 and 0.4 mol oxidizing solutions is 18 and 24 minutes. Fig. 3(b) shows the current used during the process of producing hydrogen gas. The DC current supplied to the reactor is a stable current. This current data is then used to calculate the volume of hydrogen gas produced under Faraday's law shown in Table $\mathbf{1 .}$

\subsection{Calculation of $\mathrm{H}_{2}$ volume production based on Faraday's law}

Table 1 shows that in the fresh aliquot solution, the highest volume during the process of producing hydrogen gas is in 0.3 oxidizer solution that is $88,347 \mathrm{~mL}$. However, when the calculation of $\mathrm{H}_{2}$ volume compared to the volume of hydrogen gas experimentally, it is known that the volume of hydrogen gas in 0.2 oxidizer solution is experimentally more than the hydrogen gas volume in theoretical 0.2 oxidizing solution, the experiment is $135.352 \%$. In the old aliquot solution, the highest volume during the process of producing hydrogen gas is in 0.4 oxidizing solution of $136.929 \mathrm{~mL}$. However, if the hydrogen gas volume is theoretically compared to the hydrogen gas volume experimentally, it is known that the volume of hydrogen gas in 0.1 oxidizer solution is experimentally higher than the hydrogen gas volume in the theoretical 0.1 oxidizer solution, experiment that is $102,443 \%$.

Table 1. Volume production of gas hydrogen by fresh and old aliquot solution theoretically

\begin{tabular}{|c|c|c|c|c|}
\hline \multirow{2}{*}{$\begin{array}{c}\mathrm{FeCl}_{3} \cdot 6 \mathrm{H}_{2} \mathrm{O} \\
(\mathrm{mol})\end{array}$} & \multicolumn{2}{|c|}{ Fresh Aliquot } & \multicolumn{2}{|c|}{ Old Aliquot } \\
\hline & $\begin{array}{l}{ }^{\text {a Volume }} \\
\text { (mL) }\end{array}$ & bo $\% \mathrm{H}_{2}$ & $\begin{array}{l}{ }^{a} \text { Volume } \\
\text { (mL) }\end{array}$ & b\% $\% \mathrm{H}_{2}$ \\
\hline 0.1 & 88.347 & 117.180 & 97.615 & 102.443 \\
\hline 0.2 & 79.053 & 135.352 & 125.702 & 81.940 \\
\hline 0.3 & 67,425 & 102,643 & - & - \\
\hline 0.4 & 85,426 & 117,060 & 136.929 & 77.412 \\
\hline
\end{tabular}

${ }^{a}$ calculation of volume $\mathrm{H}_{2}$ gas, ${ }^{b}$ comparison of hydrogen gas production experimentally and calculation

The difference in the volume of hydrogen gas in experiments and calculations is due to factors affecting the production of hydrogen gas. The calculated hydrogen gas production data is calculated on the basis of ideal conditions and the electrodes used are carbon electrodes [3], while the experimental data are obtained under experimental conditions which may be affected by factors such as the use of different electrode types and the $\mathrm{pH}$ of the solution. The use of titanium and stainless steel electrodes causes more hydrogen gas production with shorter production times.

\section{Conclusion}

This research concluded that the variation of oxidation concentration has no effect on fresh aliquot solution but has an effect on old aliquot solution, this is because the storage time of the solution influences the production of $\mathrm{H}_{2}$ gas related to the variation of the oxidation concentration. The greater the oxidizing concentration, the time it takes to produce hydrogen gas is longer. In fresh aliquot solution, $\mathrm{H}_{2}$ gas volume is experimentally higher than the theoretical volume. The highest volume of gas that is in $0.2 \mathrm{~mol}$ oxidizer solution is $135.3515 \%$. In the old aliquot solution, the $\mathrm{H}_{2}$ gas volume is theoretically larger than the volume experimentally. The ratio of the highest gas volume is in the solution of 0.1 mole oxidizer of $102.4434 \%$.

This research was financially supported by Direktorat Pengembangan Bakat/Minat dan Kesejahteraan Mahasiswa (DPBMKM) through Laboratorium Mahasiswa (LABMA) Universitas Islam Indonesia. 


\section{References}

[1] Derman, E. Rahmath, A. Hartinie, M. and Moh d, K.S. Oil Palm Empty Fruit Bunches as A Pr omising Feedstock for Bioethanol Productionin Malaysia, Renewable Energy, 2018, 129 285-2 98.

[2] Fereidoni, L. and Mehdi M. Experimental Ass essment of Electrolysis Method in Production of Biodiesel from Waste Cooking Oil using $\mathrm{Z}$ eolite/Chitosan Catalyst with A Focus on Was te Biorefinery, Energy Conversion and Manage ment 147, 2017, 145-154.

[3] Gong, J. Liu, W. Du, X. Liu, C. Zhang, Z. S un, F. Yang, L. Xu, D. Guo, H. and Deng, Y. Direct Conversion of Wheat Straw into Ele ctricity with a Biomass Flow Fuel Cell Media ted by Two Redox Ion Pairs, ChemSusChem 9, 2016, 1 - 9

[4] Wahyono, Y. Wisnu I. Isnanda S. Anggistina W. and Heri, S. Analisis Produksi Gas Hidrog en pada Elektrolisis Air Laut dengan Penamba han Katalis Asam Asetat [Analysis of Hydrog en Gas Production on Sea Water Electrolysis with Addition of Acetic Acid Catalyst]. Semin ar Nasional Kimia, Jakarta, IN, 2017, pp. 7585 . 